\title{
A BIOMECHANICAL INVESTIGATION OF PROMINENT KINEMATIC FACTOR IN DRAG FLICK
}

\author{
Ikram Hussain ${ }^{1}$, Fuzail Ahmad ${ }^{2 *}$, Mohd. Tanveer Khan ${ }^{3}$ \\ *1,2,3 Department of Physical Education, Aligarh Muslim University, Aligarh, 202002, INDIA
}

*Corresponding Author: -

\begin{abstract}
: -
Drag flick being one of the most offensive and frequently used techniques during penalty corner in field hockey requires better understanding of its complex nature in order to make the skill efficient and accurate. The aim of the present study was to determine the kinematic factors which were significantly related to ball velocity during drag flick, thereby proposing the possible suggestions to improve skill efficiency. Six male intervarsity hockey players specialist in drag flicking from Aligarh Muslim University and LNIPE, Gwalior, who's ranged in age from 18-24 years, height ranged between 174-182 cm and weight ranged 59.4-66.8 kg were recruited for the study. The kinematic data was obtained by using two Canon Legria SF-10 camcorders. The subjects were asked to perform 15 consecutive drag flick trails from stationary ball position. Out of 15 trails best 6 successful trails were selected for each subject and were taken under consideration for analysis. Trail was defined as successful every time the ball hit the target whose dimensions were predetermined. The obtained videos data were analyzed using Max TRAQ 3D motion analysis software. The ball velocity was measured from ball-stick contact to the point of release of the ball. The factor analysis and product moment correlation statistical analysis were done using SPSSv.16. The results revealed that, left wrist velocity and acceleration, left elbow acceleration, both right and left shoulder angular velocity, left pelvic angular velocity, right knee velocity and acceleration, and left knee angular magnitude and angular velocity were significantly related with ball velocity and hence it is suggested that players should concentrate on these factors during training of the drag flick technique.
\end{abstract}

Keywords: Drag flick, kinematic factors, Max Traq 3D, technique and performance.

\section{(우 $(\$)$}




\section{INTRODUCTION}

The drag flick was introduced in the early 1990's by Dutch player Taco Hajo Van Den Honert, it is one of the most offensive weapons in relation to field hockey used by skilled players all over the world, from international level right down to local leagues, as a set play during penalty corners. Besides being used during penalty corners, it is also frequently used during field play as a strong pass to break lines. It is one of the most successful methods for scoring goals (Laird \& Sutherland, 2003; Mosquera et al., 2007). As the penalty corner is a set piece, a range of different plays, formations and unique routines can be rehearsed during training. Because of this it has become one of the most important facets of the modern game. The drag flick is the best offensive technique which is approximately 1.4 to 2.7 times more efficient than hitting or pushing the ball towards the goal during penalty corner (McLaughlin, 1997; Piñeiro et al., 2007; Yusoff et al., 2008). Drag flick techniques has added to new dimensions in the execution of penalty corner and therefore needs better execution technique and accuracy especially during scoring. For better understanding of the technique, one has to study the movement patterns during the performance of drag flick. Therefore, biomechanical analysis is becoming increasingly important in this regard to understand its complex nature.

Many sports biomechanists have analyzed about drag flick and found stance width and drag distance to be the variables most highly correlated with the principal criterion ball velocity. McLaughlin (1997) and Gómez et al. (2012) focused upon identifying the differences in kinematic variables of drag flicking depending upon the shot location and found a significantly greater negative angular velocity of the stick when flicking to the right than to left. López de Subijana et al., (2010); López de Subijana Hernández et al., (2011); has described the importance of creating sequential maximal velocities - from proximal to distal - of the hips, shoulders, hands and then to stick, was emphasized. The significance of performing these maximal velocities in this order has also been acknowledged as an important link transferring the momentum to stick and finally to ball maximizing the ball velocity. However, due to procedural difference and low variable consideration in previous researches, this study is designed to determine the underlying kinematic factors which are determinant during drag flick and enhancing the performance of technique.

\section{Methodology}

The study was conducted on six Intervarsity level male specialized hockey players from Aligarh Muslim University and LNIPE, Gwalior, aged 18-24 years. Their height ranged between 174-182 cm and weight between 59.4-66.8 kg. Threedimensional (3D) setup was established for the study and kinematic parameters and successful scores were used as criterion for the study. The kinematic data was obtained by using two Canon Legria SF-10 camcorders which were placed at right side of the subjects at a distance of $13 \mathrm{~m}$ and $17 \mathrm{~m}$ away from the stationary ball position, mounted at height of $1.2 \mathrm{~m}$ from the ground. The frame rates of these cameras were set on $50 \mathrm{hz}$ and speed 1/1000. Subjects were instructed to wear proper kit in order to give their best performance clip for analysis. The subjects were asked to perform 15 consecutive drag flick trails from stationary ball position. Out of 15 trails best 6 successful trails were selected for each subject and were taken under consideration for analysis. Trail was defined as successful every time the ball hit the target whose dimensions were predetermined.

The obtained data was analyzed using Max TRAQ 3D motion analysis software. The ball velocity was measured from ball-stick contact to the point of release of the ball. In order to find out the determinant kinematic factors and inter relationship between various factors, the factor analysis and Pearson's product moment correlations was applied respectively. The statistical analysis was done using SPSSv.16. with level of significance fixed at 0.05.

\section{Results \& Discussion}

The main objective of the study was to extract the determinant factors which were significantly related with ball velocity and hence the efficiency of drag flick. The results and its discussion are represented as below: 
Table 1: Descriptive analysis of fifty kinematic parameters

\begin{tabular}{|c|c|c|c|c|}
\hline S. No. & Kinematic Variables & Code & Mean & SD \\
\hline 1. & Wrist left velocity & WLV & 24.20 & 30.65 \\
\hline 2. & Elbow left velocity & ELV & 9.32 & 6.82 \\
\hline 3. & Shoulder left velocity & SLV & 7.33 & 4.50 \\
\hline 4. & Pelvic left velocity & PLV & 4.37 & 2.41 \\
\hline 5. & Knee left velocity & KLV & 4.32 & 2.76 \\
\hline 6. & Ankle left velocity & $\mathrm{ALV}$ & 3.73 & 2.48 \\
\hline 7. & Toe left velocity & TLV & 3.90 & 2.35 \\
\hline 8. & Wrist right velocity & WRV & 12.87 & 5.53 \\
\hline 9. & Elbow right velocity & ERV & 19.35 & 28.24 \\
\hline 10. & Shoulder right velocity & SRV & 9.30 & 6.66 \\
\hline 11. & Pelvic right velocity & PRV & 5.32 & 3.44 \\
\hline 12. & Knee right velocity & KRV & 15.12 & 16.35 \\
\hline 13. & Ankle right velocity & ARV & 21.65 & 19.61 \\
\hline 14. & Toe right velocity & TRV & 20.58 & 21.17 \\
\hline 15. & Wrist left acceleration & WLA & -38.36 & 101.34 \\
\hline 16. & Elbow left acceleration & ELA & -20.27 & 30.33 \\
\hline 17. & Shoulder left acceleration & SLA & -12.72 & 19.61 \\
\hline 18. & Pelvic left acceleration & PLA & -18.12 & 26.43 \\
\hline 19. & Knee left acceleration & KLA & -13.58 & 19.25 \\
\hline 20. & Ankle left acceleration & ALA & -3.25 & 8.27 \\
\hline 21. & Toe left acceleration & TLA & -7.39 & 7.57 \\
\hline 22. & Wrist right acceleration & WRA & 3.07 & 105.83 \\
\hline 23. & Elbow right acceleration & ERA & -3.18 & 85.34 \\
\hline 24. & Shoulder right acceleration & SRA & -1.70 & 23.10 \\
\hline 25. & Pelvic right acceleration & PRA & -0.56 & 11.73 \\
\hline 26. & Knee right acceleration & KRA & 7.16 & 118.54 \\
\hline 27. & Ankle right acceleration & ARA & 24.43 & 118.96 \\
\hline 28. & Toe right acceleration & TRA & 58.55 & 83.74 \\
\hline 29. & Elbow left angular magnitude & ELAM & 118.11 & 17.98 \\
\hline 30. & Shoulder left angular magnitude & SLAM & 66.82 & 33.42 \\
\hline 31. & Pelvic left angular magnitude & PLAM & 72.34 & 21.86 \\
\hline 32. & Knee left angular magnitude & KLAM & 104.63 & 27.51 \\
\hline 33. & Ankle left angular magnitude & ALAM & 93.58 & 41.87 \\
\hline 34. & Wrist right angular magnitude & WRAM & 115.15 & 20.52 \\
\hline 35. & Elbow right angular magnitude & ERAM & 112.68 & 22.38 \\
\hline 36. & Shoulder right angular magnitude & SRAM & 82.23 & 22.90 \\
\hline 37. & Pelvic right angular magnitude & PRAM & 85.01 & 27.54 \\
\hline 38. & Knee right angular magnitude & KRAM & 103.54 & 32.22 \\
\hline 39. & Ankle right angular magnitude & ARAM & 84.43 & 32.37 \\
\hline 40. & Elbow left angular velocity & ELAV & -56.72 & 261.80 \\
\hline 41. & Shoulder left angular velocity & SLAV & -5.45 & 169.39 \\
\hline 42. & Pelvic left angular velocity & PLAV & 102.80 & 135.33 \\
\hline 43. & Knee left angular velocity & KLAV & 68.54 & 123.76 \\
\hline 44. & Ankle left angular velocity & ALAV & -7.16 & 98.57 \\
\hline 45. & Wrist right angular velocity & WRAV & 21.08 & 287.36 \\
\hline 46. & Elbow right angular velocity & ERAV & -74.35 & 147.64 \\
\hline 47. & Shoulder right angular velocity & SRAV & 36.27 & 157.44 \\
\hline 48. & Pelvic right angular velocity & PRAV & -59.59 & 272.14 \\
\hline 49. & Knee right angular velocity & KRAV & 13.40 & 223.13 \\
\hline 50. & Ankle right angular velocity & ARAV & -105.32 & 200.15 \\
\hline 51. & Ball velocity & Ball & 87.57 & 148.48 \\
\hline
\end{tabular}

Table 1 shows the descriptive statistics analysis of fifty-one kinematic parameters of the drag flicker. The mean and standard deviation (SD) of the kinematic parameters were taken for the study.

Factor Analysis:

The purpose of factor analysis is to explore the under lying factors that explains the correlations among a set of variables. The relationship of each variable to the underlying factor is expressed by so called factor loading. 
Table 2: Representing Factor loading of factor I

\begin{tabular}{|l|l|l|l|}
\hline S.No. & Kinematic Variables & Code & Factor Loading \\
\hline 1 & Pelvic left velocity & PLV & 0.740 \\
\hline 2 & Knee left velocity & KLV & 0.868 \\
\hline 3 & Pelvic right velocity & PRV & 0.883 \\
\hline 4 & Knee right velocity & KRV & $\mathbf{0 . 9 0 4}$ \\
\hline 5 & Ankle right velocity & ARV & 0.765 \\
\hline 6 & Shoulder left acceleration & SLA & 0.520 \\
\hline 7 & Elbow right acceleration & ERA & 0.565 \\
\hline 8 & Shoulder right acceleration & SRA & 0.684 \\
\hline 9 & Pelvic right acceleration & PRA & 0.397 \\
\hline 10 & Toe right acceleration & TRA & 0.692 \\
\hline 11 & Pelvic left angular magnitude & PLAM & 0.643 \\
\hline
\end{tabular}

Factor I (Table 2): The highest factor loading of 0.904 is attributed to knee right velocity as shown in the above table. The right knee velocity acts as a medium of transference of momentum from the toe the pelvis which during swinging action carries the ball forward due to the conservation of momentum, thus generating the speed of the ball to maximum during drag flick.

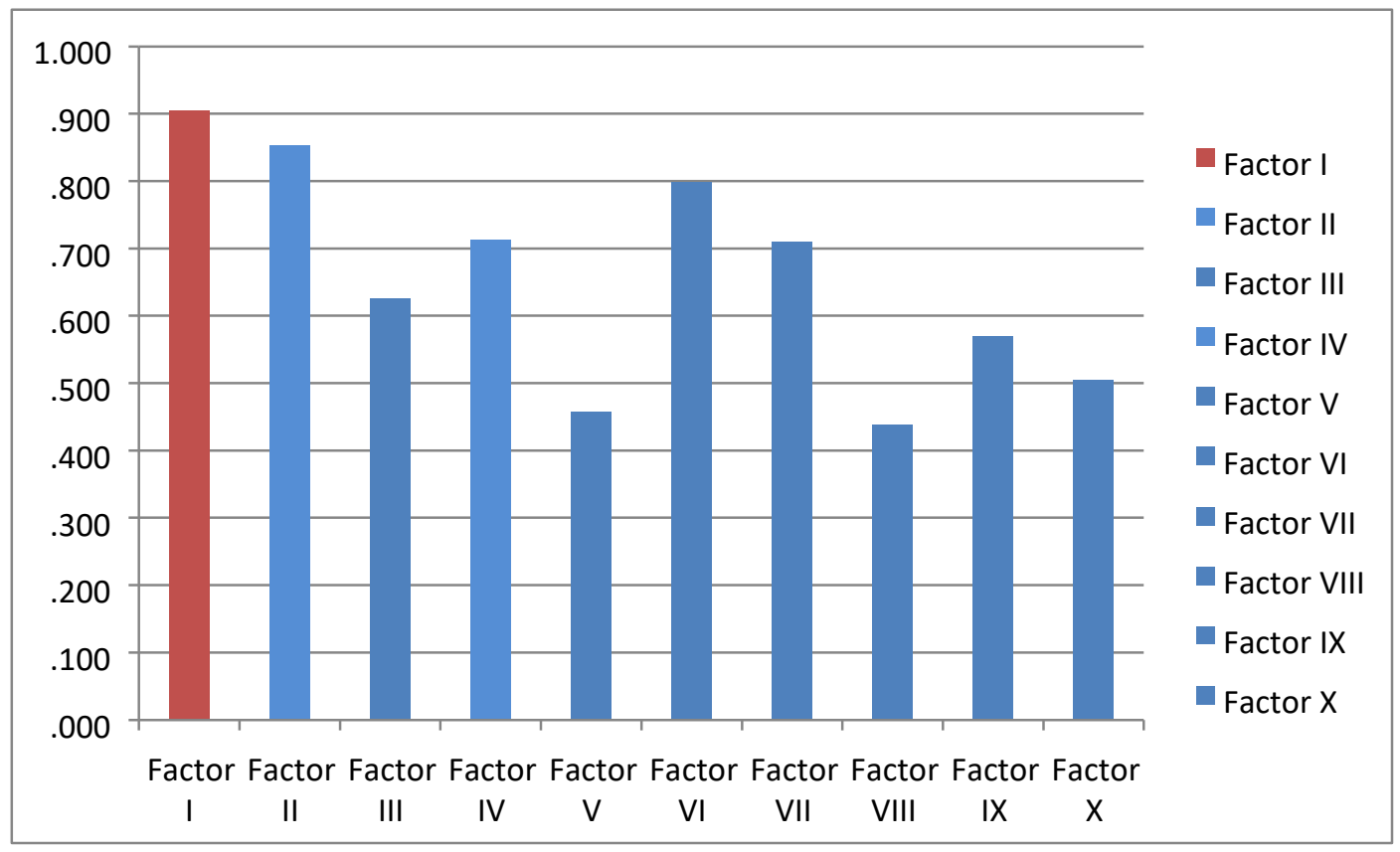

Table 3: Representing Factor Loading of factor II

\begin{tabular}{|l|l|l|l|}
\hline S.No. & Kinematic Variables & Code & Factor Loading \\
\hline 1 & Wrist left velocity & WLV & $\mathbf{0 . 8 5 3}$ \\
\hline 2 & Elbow left velocity & ELV & 0.823 \\
\hline 3 & Ankle left velocity & ALV & 0.579 \\
\hline 4 & Toe left velocity & TLV & 0.810 \\
\hline 5 & Wrist right velocity & WRV & 0.844 \\
\hline 6 & Elbow right velocity & ERV & 0.764 \\
\hline 7 & Shoulder right velocity & SRV & 0.743 \\
\hline 8 & Toe right velocity & TRV & 0.813 \\
\hline 9 & Ankle left acceleration & ALA & 0.514 \\
\hline 10 & Toe left acceleration & TLA & 0.416 \\
\hline 11 & Shoulder left angular magnitude & SLAM & 0.710 \\
\hline 12 & Ankle left angular magnitude & ALAM & 0.749 \\
\hline 13 & Shoulder right angular magnitude & SRAM & 0.554 \\
\hline 14 & Ankle right angular magnitude & ARAM & 0.642 \\
\hline 15 & Shoulder left angular velocity & SLAV & 0.537 \\
\hline 16 & Ankle left angular velocity & ALAV & 0.345 \\
\hline
\end{tabular}


Factor II (Table 3): Wrist left velocity exhibits significant positive factor loading of 0.853 . Flicking is all in the wrists. The wrist needs to rotate the stick enough so that stick face is angled to throw the ball into the air, but not so far that the ball will slip over the head while performing the push action. Besides wrist right velocity, elbow left velocity and toe left velocity are also responsible for swinging of the particular articulation and transfer the moment to their relative parts of the body that play a dominant role in factor II.

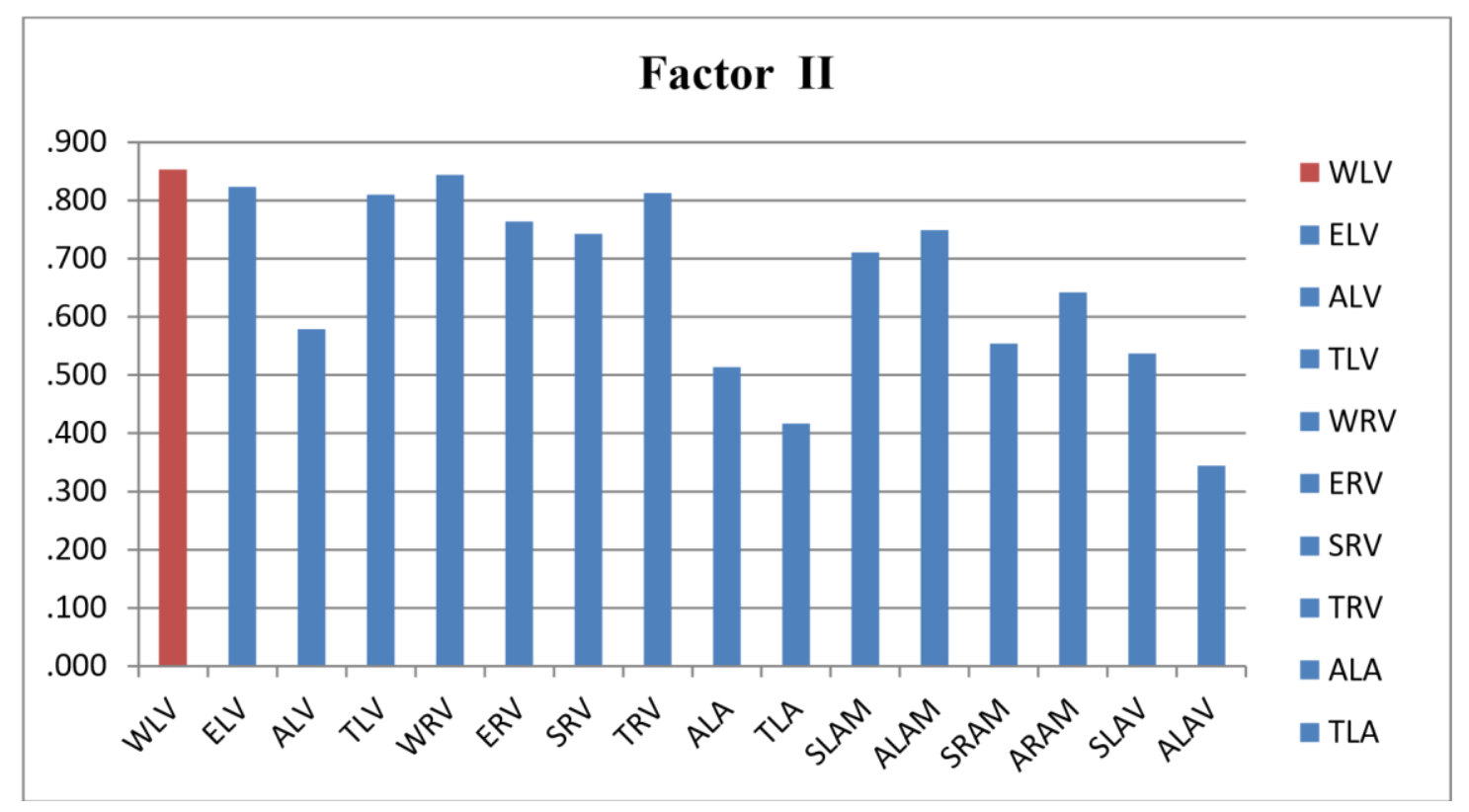

Table 4: Representing Factor Loading of factor III

\begin{tabular}{|l|l|l|l|}
\hline S.No. & Kinematic Variables & Code & Factor Loading \\
\hline 1 & Shoulder left velocity & SLV & 0.544 \\
\hline 2 & Wrist left acceleration & WLA & $\mathbf{0 . 6 2 5}$ \\
\hline 3 & Pelvic left acceleration & PLA & 0.200 \\
\hline 4 & Wrist right acceleration & WRA & 0.433 \\
\hline 5 & Elbow right angular velocity & ERAV & 0.521 \\
\hline 6 & Pelvic right angular velocity & PRAV & 0.155 \\
\hline 7 & Ankle right angular velocity & ARAV & 0.249 \\
\hline
\end{tabular}

Factor III (Table 4): The table depicts the maximum factor loading for Wrist left acceleration (WLA) which is 0.625 , thus playing a significant role in factor III. The players are having their left hand closer to their bodies, so that they can create a greater angle in order to increase the acceleration of left wrist during cross over step. Furthermore, the work of the left shoulder is pointing in the direction of drag flick and wrapping the stick around and below the left shoulder for enhancement of the shoulder left velocity.

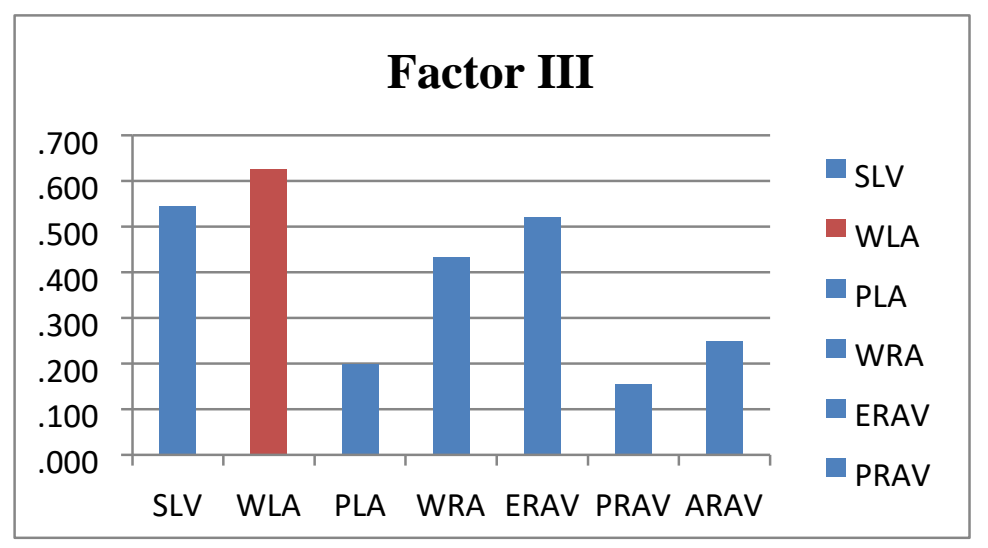

Table 5: Representing Factor Loading of factor IV

\begin{tabular}{|l|l|l|l|}
\hline S.No. & Kinematic Variables & Code & Factor Loading \\
\hline 1 & Knee left angular magnitude & KLAM & $\mathbf{0 . 7 1 3}$ \\
\hline 2 & Wrist right angular magnitude & WRAM & 0.589 \\
\hline 3 & Elbow left angular velocity & ELAV & 0.316 \\
\hline
\end{tabular}


Factor IV (Table 5): The maximum factor loading is of knee left angular magnitude which is 0.713 as evident from the above table. The knee left angular magnitude is responsible for production of momentum and transferring it from one part to another with the help of degree of knee angles as well as horizontal displacement. The other two factors are prime prelude for augmentation of ball velocity and enhancement performance in the area of drag flick.

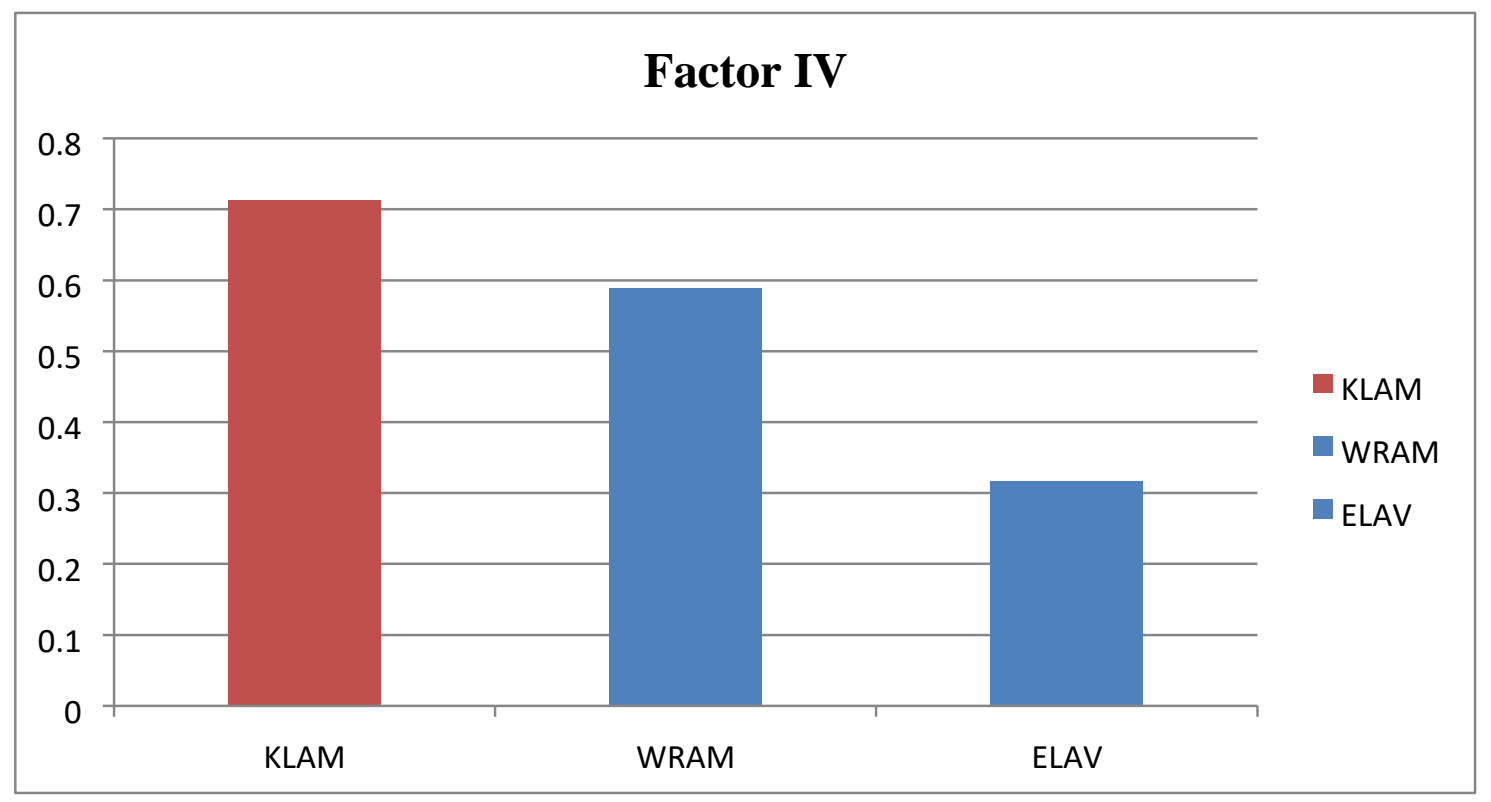

Table 6: Representing Factor Loading of factor $\mathrm{V}$

\begin{tabular}{|l|l|l|l|}
\hline S.no. & Kinematic Variables & Code & Factor Loading \\
\hline 1 & Knee right acceleration & KRA & $\mathbf{0 . 4 5 7}$ \\
\hline 2 & Elbow left angular magnitude & ELAM & 0.446 \\
\hline 3 & Pelvic right angular magnitude & PRAM & 0.414 \\
\hline
\end{tabular}

Factor V (Table 6): The knee right acceleration is having maximum factor loading of 0.457 . The amorousness of this factor is providing a channel to develop or reduce acceleration with the phases of knee right horizontal displacement that is efficacy of the drag flick skill. The other parameter is the elbow left angular magnitude that maintains the coordination between both hands and sticks.

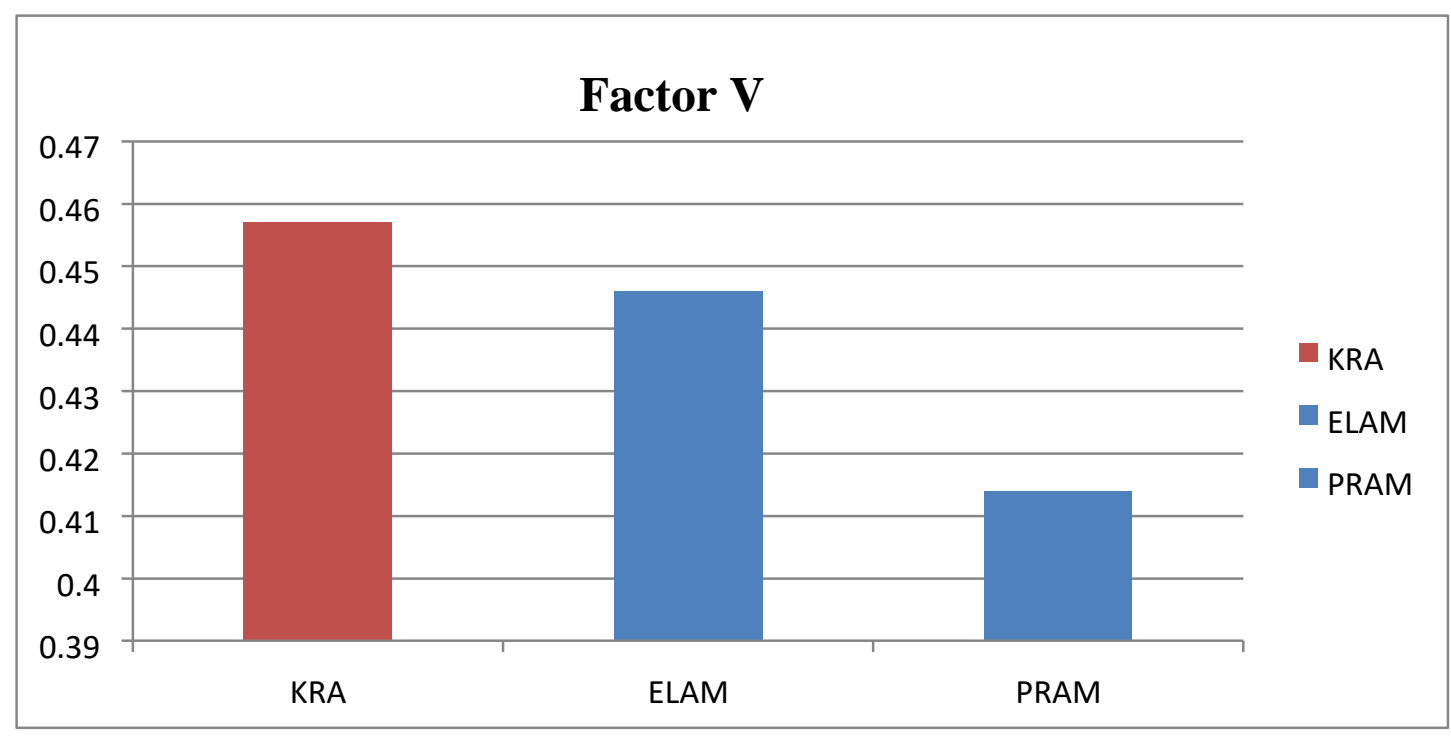

Table 7: Representing Factor Loading of factor VI

\begin{tabular}{|l|l|l|l|}
\hline S.No. & Kinematic Variables & Code & Factor Loading \\
\hline 1 & Knee right angular magnitude & KRAM & 0.511 \\
\hline 2 & Shoulder right angular velocity & SRAV & $\mathbf{0 . 7 9 8}$ \\
\hline
\end{tabular}


Factor VI (Table 7): The factor loading of shoulder right angular velocity is 0.798 which is maximum, playing a tremendous effect in this factor. Basically the shoulder right contains all short pocket of forces that are taken from various lower parts of body and produced maximum angular velocity.

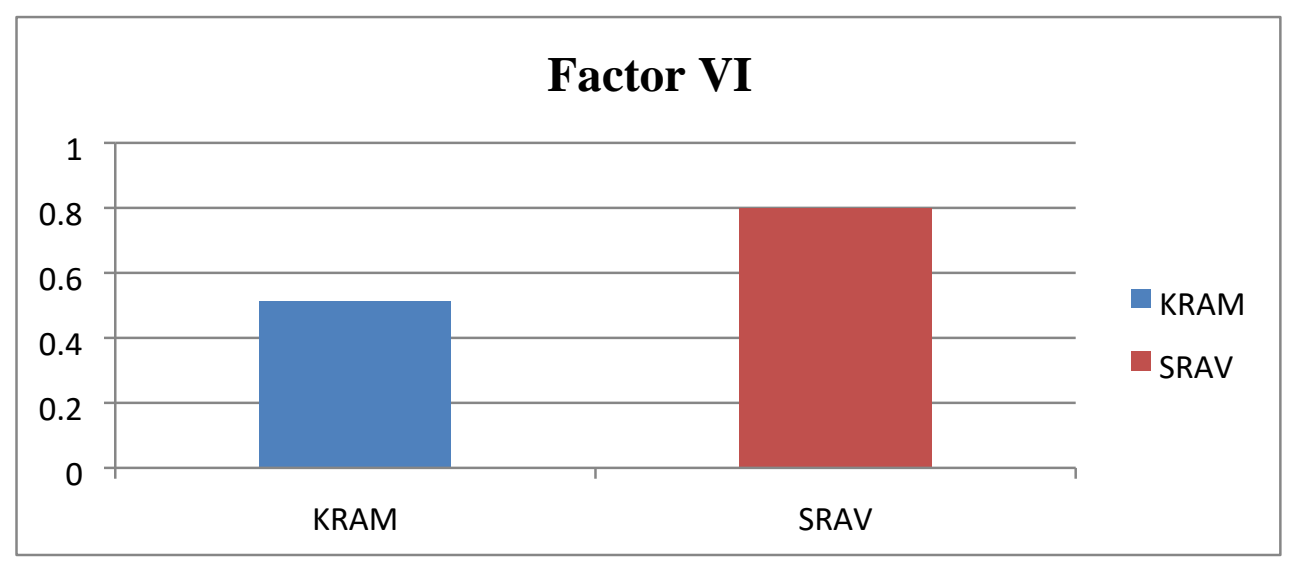

Table 8: Representing Factor Loading of factor VII

\begin{tabular}{|l|l|l|l|}
\hline S.No. & Kinematic Variables & Code & Factor Loading \\
\hline 1 & Knee left acceleration & KLA & 0.386 \\
\hline 2 & Ankle right acceleration & ARA & 0.700 \\
\hline 3 & Pelvic left angular velocity & PLAV & $\mathbf{0 . 7 0 9}$ \\
\hline 4 & Knee right angular velocity & KRAV & 0.561 \\
\hline
\end{tabular}

Factor VII (Table 8): The maximum factor loading is of pelvic left angular velocity equal to 0.709 . During the rotation of the body the angular velocity of the pelvic changes from right negative to left positive, because left leg raises and then swings with the help of left side of the hip. The ankle right acceleration is providing momentum to its lower extremities for shifting the whole weight from right to left feet and it becomes easier to perform skill of drag flick.

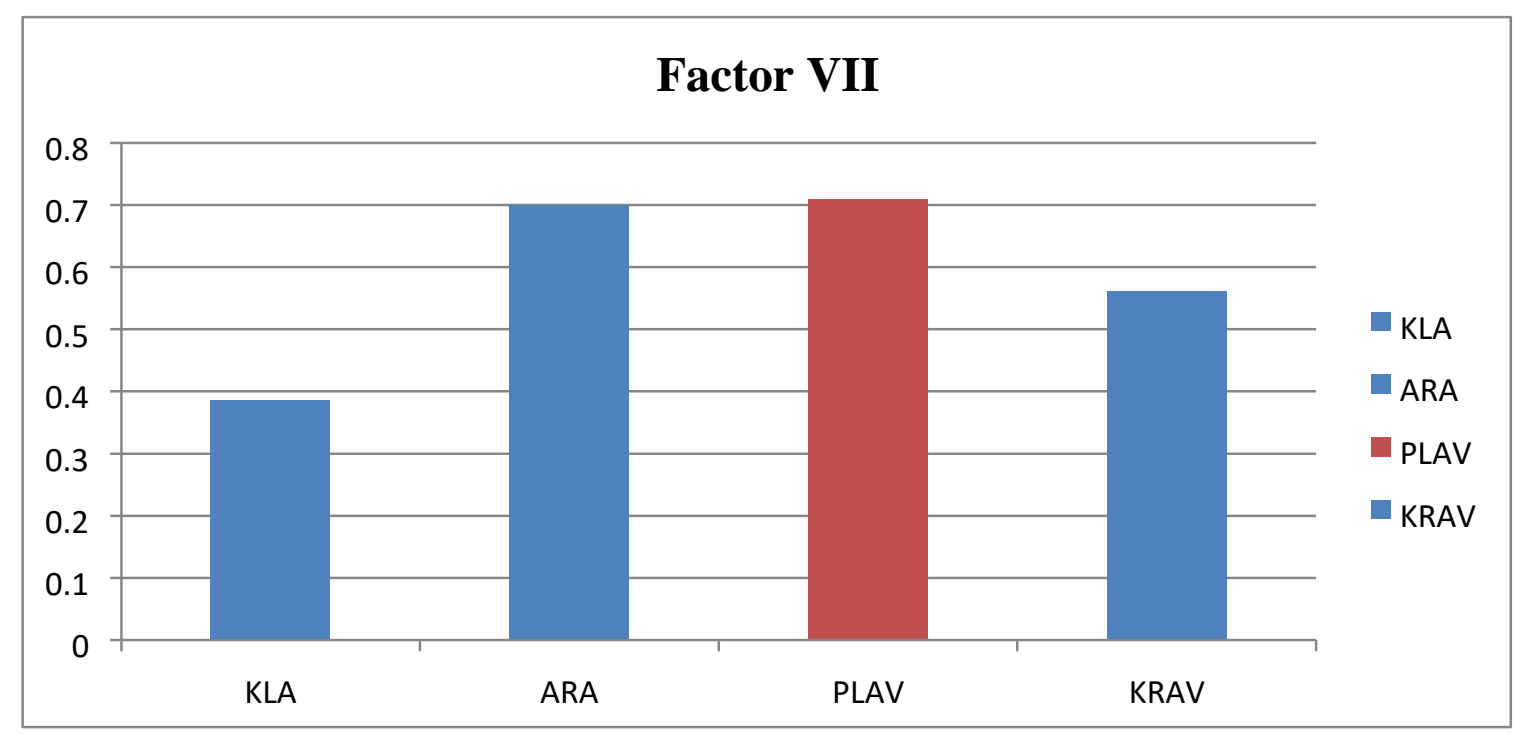

Table 9: Representing Factor Loading of factor VIII

\begin{tabular}{|l|l|l|l|}
\hline S.No. & Kinematic Variables & Code & Factor Loading \\
\hline 1 & Shoulder left angular velocity & SLAV & $\mathbf{0 . 4 3 9}$ \\
\hline
\end{tabular}

Factor VIII (Table 9): The factor loading of shoulder left angular velocity is 0.439 . The left shoulder is pointed in the direction of the goal, doing this aid in the accuracy and increases the angular velocity keeping the ball on target 


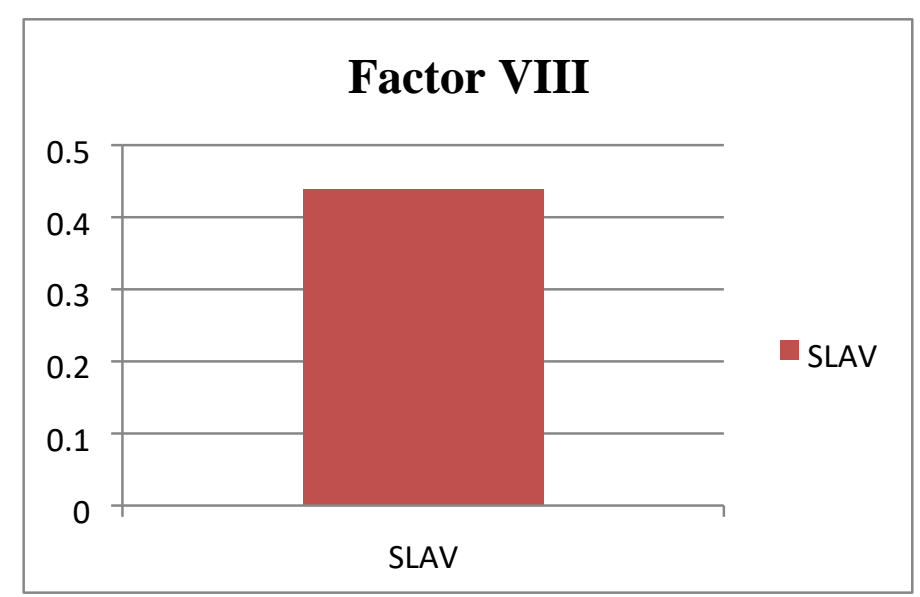

Table 10: Representing Factor Loading of factor IX

\begin{tabular}{|l|l|l|l|}
\hline S.No. & Kinematic Variables & Code & Factor Loading \\
\hline 1 & Elbow left acceleration & ELA & $\mathbf{0 . 5 6 9}$ \\
\hline 2 & Elbow right angular magnitude & ERAM & 0.499 \\
\hline 3 & Wrist right angular velocity & WRAV & 0.301 \\
\hline
\end{tabular}

Factor IX (Table 10): The maximum factor loading is of elbow left acceleration equal to 0.569. It starts with slower movement but with the passage of time gradually increases due to generated and transfer force from segment to segment. The elbow right angular magnitude is also boon due achieving angles, swing and displacement to encourage ball velocity during drag flick.

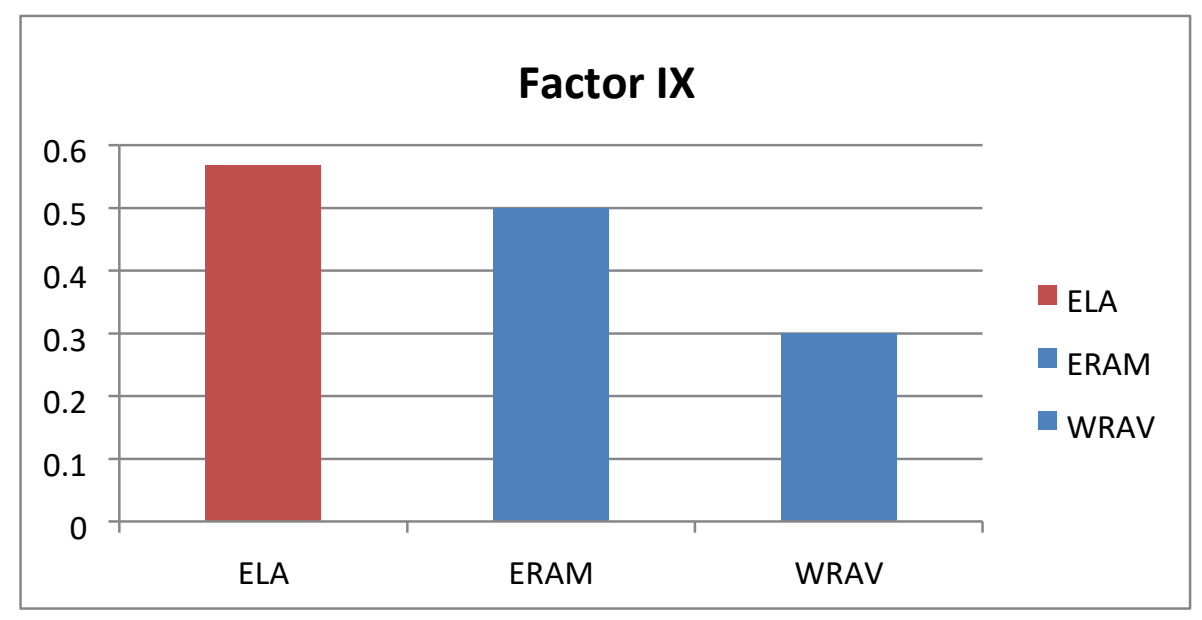

Table 11: Representing Factor Loading of factor $X$

\begin{tabular}{|l|l|l|l|}
\hline S.No. & Kinematic Variables & Code & Factor Loading \\
\hline 1 & Knee left angular velocity & KLAV & $\mathbf{0 . 5 0 5}$ \\
\hline
\end{tabular}

Factor 10 (Table 11): The factor loading of knee left angular velocity is 0.505 that is a single prominent factor loading in factor 10. The work of this parameter is bending and swinging knee to increases angular velocity that is necessary for enhancement of ball velocity.

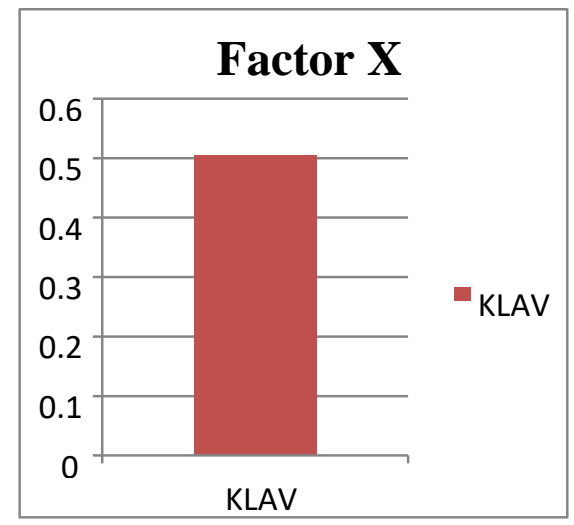


Table 12: Correlation of Factors with Ball velocity.

\begin{tabular}{|l|l|}
\hline \multicolumn{2}{|l|}{ Correlations } \\
\hline Factors & Ball \\
\hline WLV & 0.91 \\
\hline KRV & 0.09 \\
\hline WLA & -0.10 \\
\hline ELA & -0.28 \\
\hline KRA & -0.06 \\
\hline KLAM & -0.15 \\
\hline SLAV & 0.22 \\
\hline PLAV & -0.11 \\
\hline KLAV & 0.00 \\
\hline SRAV & -0.14 \\
\hline
\end{tabular}

The correlation of factors with ball velocity is represented through graphs as below;

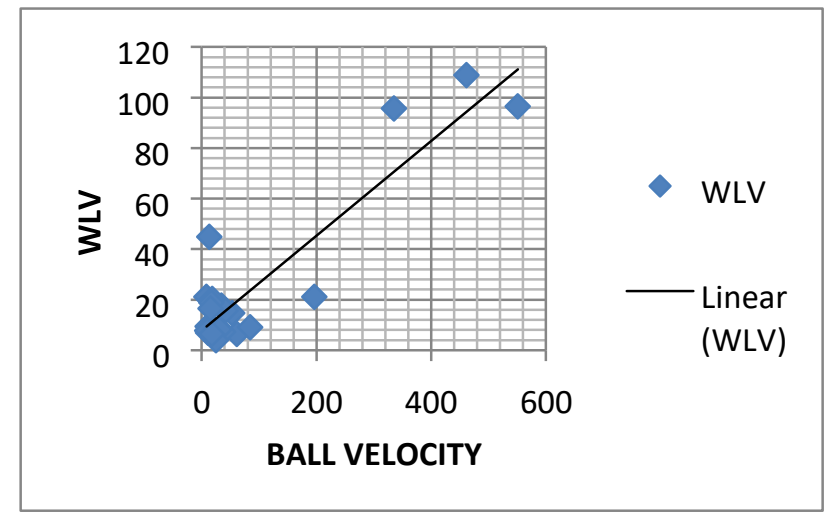

Figure 1: The wrist left velocity is exhibiting significant positive correlation with ball velocity which is 0.91thereby playing a significant role in enhancing the performance of drag flick in hockey.

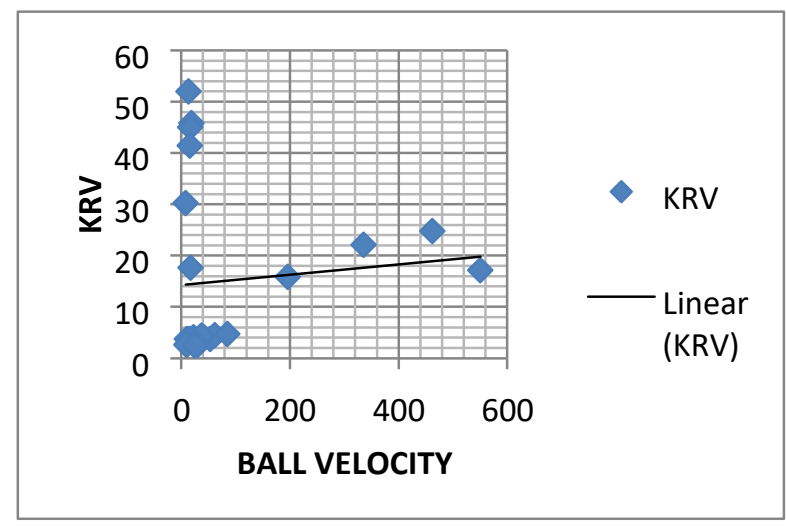

Figure 2: The knee right velocity is having a positive correlation of 0.09 with ball velocity. The graph shows the gradual increase in the rate of knee right velocity with ball velocity.

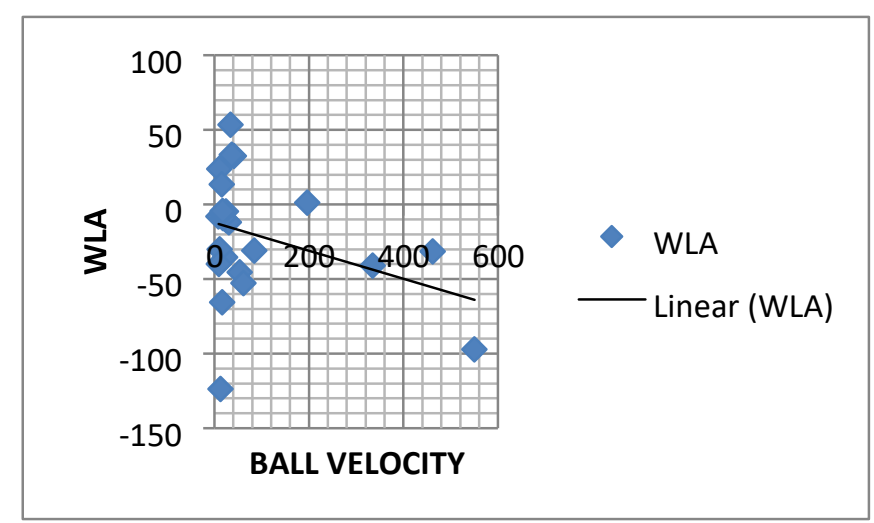

Figure 3: The correlation coefficient of wrist left acceleration is $\mathbf{- 0 . 1 0}$ that is demonstrating significant negative correlation with wrist left acceleration and ball velocity. 


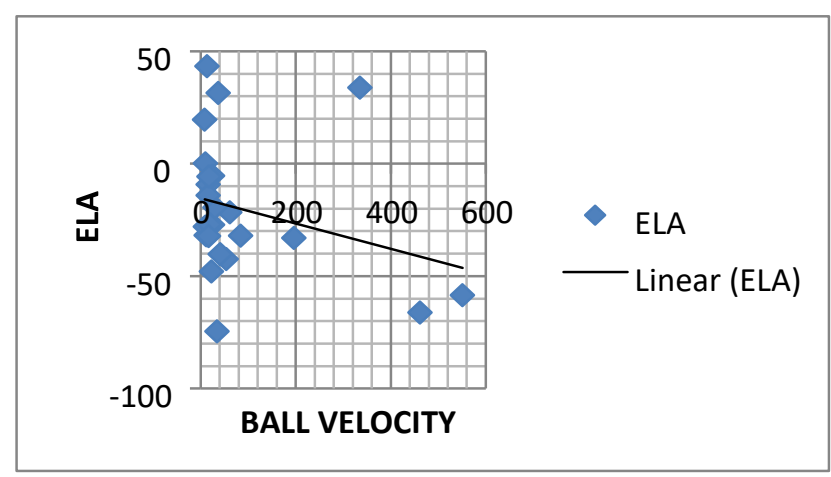

Figure 4: The elbow left acceleration is exhibiting a correlation coefficient of $\mathbf{- 0 . 2 8}$ with elbow left acceleration and ball velocity. It is supported by the other parameters with the help of negatively affect for ameliorate performance while drag flick in hockey.

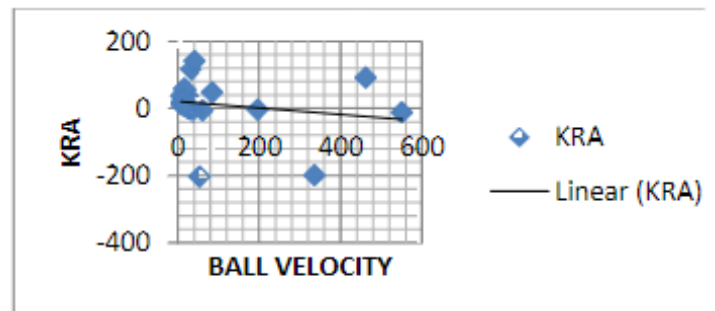

Figure 5: Thecorrelation coefficient of kneeright acceleration is $\mathbf{- 0 . 0 6}$ associated to direction towards negative correlation with ball velocity and knee right acceleration in hockey.

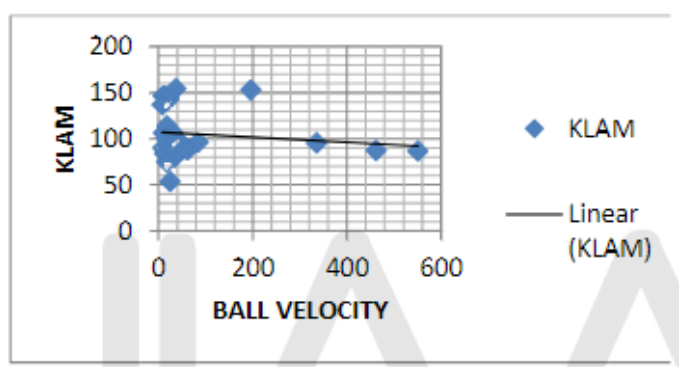

Figure 6: Thecorrelation coefficient ofknee left angular magnitude is $\mathbf{- 0 . 1 5 t h a t ~ i s ~ a s s o c i a t e d ~ t o ~ n e g a t i v e ~}$ correlation with angular magnitude and ball velocity. Basically, itprovidesdirection like shoulder articulation towards target area. At the timeofflicking, the body weight shiftsfrombackward to forward due to production ofless angular magnitude in left knee.

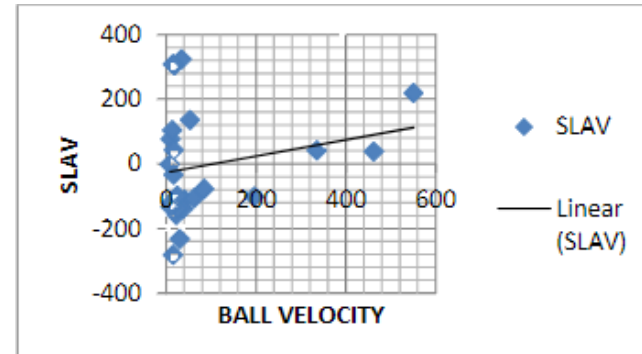

Figure 7: The shoulder left angular velocity is having significantly positive correlation of 0.22 with ball velocity and shoulder left angular velocity.

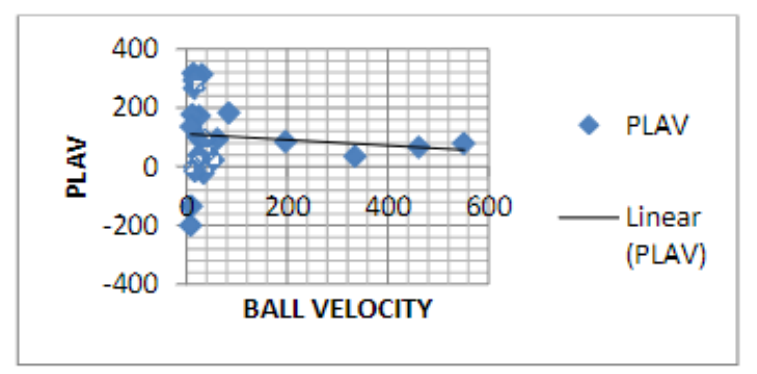

Figure 8: The pelvic left angular velocity is a negative correlation coefficient of a $\mathbf{- 0 . 1 1}$ with ball velocity and its parameters. Basically, the left side of pelvic is going to be like some fix moment which creates an opportunity to increase the momentum to the right side of pelvic thereby increasing its angular velocity. 


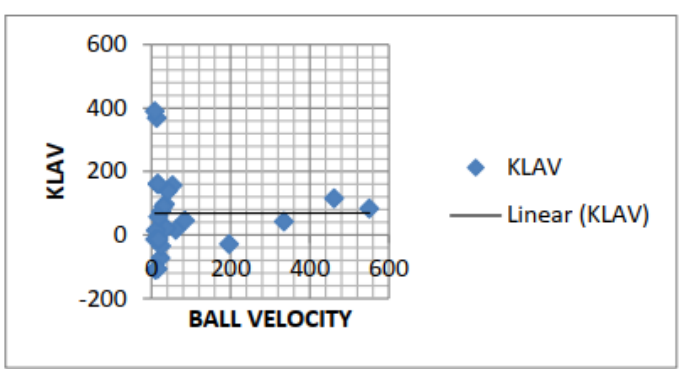

Figure 9: The knee left angular velocity is 0.00 having neither positive nor negative correlation with ball velocity and knee left angular velocity.

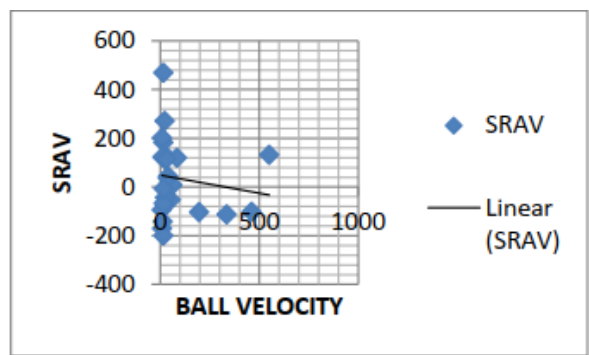

Figure 10: The shoulder right angular velocity is having a negative correlation coefficient of $\mathbf{- 0 . 1 4}$ with ball velocity and shoulder right angular velocity.

\section{Conclusion:}

In this study of kinematic analysis of body during drag flick, various kinematic factors were determined which were affecting the skill and were significantly related with ball velocity. These include, left wrist velocity and acceleration, left elbow acceleration, both right and left shoulder angular velocity, left pelvic angular velocity, right knee velocity and acceleration, and left knee angular magnitude and angular velocity. Hence, we can conclude that the above determinants should be given due consideration in order to enhance the efficiency of drag flick.

\section{References}

[1].Ansari, N.W., Bari, M.A., Hussain, I. \& Ahmad, F. (2014). Three-Dimensional Biomechanical Analysis of the Drag in Penalty Corner Drag Flick Performance. Journal of Education and Practice. Vol. 5(20), 9196.

[2].Ansari, N.W., Bari, M.A., Hussain, I. \& Ahmad, F. (2014). Three-dimensional kinematic analysis of the drag flick for accuracy. International Journal of Applied Sciences and Engineering Research, Vol. 3(2), 431-435.

[3].Bari, M. A., Ansari, N.W., Hussain, I., Ahmad, F. \& Khan, M. A. (2014). Three-Dimensional Analysis of Variation between Successful and Unsuccessful Drag flick Techniques in Field Hockey. International Journal of Research Studies in Science, Engineering and Technology. Vol. 1(2), 74-78.

[4].Bari, M.A., Ansari, N.W., Ahmad, F. \& Hussain, I. (2014). Three-Dimensional Analysis of Drag-Flick in The Field Hockey Of University Players. Advances in Physics Theories and Applications, Vol. 29, 8793.

[5].Bartlett, R. (2007). Introduction to sports biomechanics. London: Rutledge.

[6].Glencross, D. (1985). 100 Hockey Tips. Rigby Australia.

[7].Ikram, H., Saleem A., Sartaj K. (2012). Biomechanical study on drag flick in field hockey. International journal of behavioral social and movement sciences,1(3).

[8].Laird. P., Sutherland, P. (2003). Penalty corners in field hockey: A guide to success. Int J Perform Anal Sport. 2003;3(1):19-26.

[9].López de Subijana, C., Juarez, D., Mallo, J., Navarro, E. (2010). Biomechanical analysis of the penalty corner Drag flick of elite male and female hockey players. Sports Biomechanics 9(2), 7278

[10]. McLaughlin, P. (1997). Three-dimensional biomechanical analysis of the hockey drag flick full report. Belconnen, A.C.T., Australia: Australian Sports Commission.

[11]. Piñeiro R., Sampedro J., Refoyo I. (2007). Differences between international men's andwomen's teams in the strategic action of the penalty corner in field hockey. International Journal of Performance Analysis in Sport 7(3), 6783

[12]. Piñeiro, R. (2008). Observación y análisis de la acción de gol en hockey hierba. [The goal play in field hockey: observation and analysis] Sevilla: Wanceulen; (In Spanish)

[13]. Yusoff, S., Hasan, N., Wilson, B. (2008). Three-dimensional biomechanical analysis of the hockey drag flick. 